\title{
Analisis Deskriptif Kepuasan Karyawan Lembaga Keuangan Perbankan
}

\author{
Christsanto J., Negoro N.P., dan Rahmawati Y. \\ Departemen Manajemen Bisnis, Fakultas Bisnis dan Manajenen Teknologi, Institut Teknologi Sepuluh Nopember \\ (ITS) \\ e-mail: jeremy.christsanto@gmail.com
}

\begin{abstract}
Abstrak-Lembaga Keuangan Perbankan sangat perlu untuk memperhatikan kepuasan nasabahnya, karena kepuasan nasabah mampu meningkatkan kinerja keuangan perusahaan. Maka dari itu, untuk meningkatkan kepuasan nasabah, pelayanan perlu ditingkatkan. Peningkatan pelayanan dilakukan dengan cara meningkatkan kepuasan karyawan frontliner. Peningkatkan kepuasan karyawan frontliner akan membuat karyawan menjadi lebih setia dan ilmu yang dimiliki oleh karyawan untuk melayani semakin meningkat. Penelitian ini bertujuan untuk mengidentifikasi dan mengurutkan peringkat faktor-faktor yang mempengaruhi kepuasan karyawan frontliner di Surabaya. Data untuk penelitian dikumpulkan dengan menggunakan instrumen kuesioner. Jumlah data terkumpul adalah sebanyak 71 buah. Analisis yang digunakan adalah analisis scatter plot yang terdiri dari mean dan standar deviasi untuk mengurutkan peringkat-peringkat faktor kepuasan karyawan. Hasil yang didapatkan membuktikan bahwa pelatihan dan pengembangan mempunyai peringkat tertinggi yang mempengaruhi kepuasan karyawan frontliner, sementara pemberdayaan dan partisipasi mempunyai peringkat terendah yang mempengaruhi karyawan frontliner.
\end{abstract}

Kata Kunci-Kepuasan kerja karyawan, karyawan lembaga keuangan perbankan, kinerja keuangan,

\section{PENDAHULUAN}

$\mathrm{K}$ EPUASAN nasabah merupakan salah satu hal yang perlu untuk diperhatikan terutama pada industri lembaga keuangan perbankan. Sikap karyawan frontliner lembaga keuangan perbankan yang tidak menyenangkan dapat mempengaruhi kepuasan nasabah [1].

Dalam penelitian terdahulu, ditemukan bahwa kepuasan nasabah berpengaruh positif terhadap kinerja keuangan [2]. Hal tersebut terjadi disebabkan oleh kepuasan karyawan yang rendah. Maka dari itu, perlu bagi perusahaan untuk meningkatkan atmosfir kerja yang lebih baik [3]. Dengan atmosfir kerja yang lebih baik, karyawan akan menjadi lebih puas dan setia kepada perusahaan, sehingga mampu memberikan pelayanan dengan kualitas yang terbaik [4].

Heskett et.al. [5], menyatakan bahwa perusahaan perlu untuk meningkatkan kepuasan kerja karyawan-karyawannya, karena karyawan yang puas dapat bekerja dengan baik dan loyal kepada perusahaan. Dengan demikian, pelayanan yang diberikan oleh perusahaan akan meningkat seiring dengan pengalaman dan ilmu yang dimiliki oleh karyawan. Ilmu tersebut akan menjadi intangible assets bagi perusahaan. Intangible assets tersebut merupakan modal intelektual perusahaan yang dapat meningkatkan kinerja keuangan perusahaan, terutama pada lembaga keuangan perbankan [6]. Penelitian terkait dengan kepuasan kerja karyawan pada lembaga keuangan perbankan belum banyak dilakukan, maka dari itu penelitian ini bertujuan untuk mengidentifikasi dan mengurutkan peringkat faktor-faktor yang mempengaruhi kepuasan karyawan frontliner perbankan di Surabaya.

\section{TINJAUAN PUSTAKA}

\section{A. Kepuasan Kerja Karyawan}

Kepuasan kerja karyawan adalah perasaan senang yang kemudian membuat sesorang mampu untuk memenuhi semua pekerjaannya dengan baik atau menyelesaikan nilai utama dari pekerjaan tersebut dengan baik [7]. Untuk mengukur kepuasan karyawan lembaga keuangan perbankan, indikator yang digunakan adalah gaji dan promosi, pelatihan dan pengembangan, beban kerja, kondisi fisik tempat kerja, peraturan tempat kerja, pemberdayaan dan partisipasi, penghargaan dan pengakuan kerja, pengawasan, dan kerjasama tim.

\section{B. Gaji dan Promosi}

Gaji didefinisikan sebagai sejumlah uang yang diberikan kepada karyawan sebagai hasil dari kerja yang telah dilakukan [8]. Promosi didefinisikan sebagai peningkatan menuju posisi dengan tantangan, tanggung jawab, dan otoritas yang lebih besar daripada posisi sebelumnya [9].

\section{Pelatihan dan Pengembangan}

Pelatihan dan pengembangan adalah kesempatan yang diberikan oleh perusahaan untuk memperluas pengetahuan dan keahlian untuk mencapai kerjasama tim yang lebih efisien dan mencapai pengembangan diri yang baik [8]

\section{Beban Kerja}

Beban kerja adalah jumlah tugas dalam satu pekerjaan tersebut yang harus diselesaikan dalam kurun waktu tertentu[9].

\section{E. Kondisi Fisik Tempat Kerja}

Kondisi fisik tempat kerja adalah faktor-faktor yang mempengaruhi kenyamanan tempat kerja [8].

\section{F. Peraturan Tempat Kerja}

Peraturan tempat kerja didefinisikan sebagai peraturan yang telah ditetapkan oleh perusahaan untuk mengatur kinerja karyawan [9]. 


\section{G. Pemberdayaan dan Partisipasi}

Pemberdayaan adalah langkah untuk menciptakan nilai bagi karyawan agar mereka mampu mengerjakan pekerjaannya secara independen [8].

Partisipasi didefnisikan sebagai keterlibatasn karyawan dalam manajemen dan pembuatan keputusan terkait dengan strategi, tujuan, dan kebijakan perusahaan [8].

\section{H. Penghargaan dan Pengakuan Kerja}

Penghargaan dan pengakuan kerja didefinisikan sebagai penghargaan dan pengakuan atas kinerja bagus yang telah dilakukan oleh karyawan [8].

\section{Pengawasan}

Pengawasan didefinisikan sebagai pengawasan yang dilakukan oleh supervisor untuk membantu karyawan bekerja atau memberikan arahan ketika karyawan tidak memahami konteks yang harus dikerjakan [10]

\section{J. Kerjasama Tim}

Kerjasama tim didefinisikan sebagai langkah untuk meningkatkan motivasi, otonomi karyawan, pengaruh, dan pembentukan ikatan yang kuat dengan anggota lainnya [8].

\section{METODE PENELITIAN}

\section{A. Desain Penelitian}

Penelitian ini merupakan penelitian eksploratori. Penelitian dilakukan di Surabaya. Objek penelitian ini adalah lembaga keuangan perbankan di Surabaya. Objek amatannya adalah karyawan frontliner yaitu customer service, teller, dan analis kredit dari bank BNI, CIMB Niaga, dan Mandiri.

\section{B. Pengumpulan Data}

Pengumpulan data dilakukan dengan penyebaran kuesioner secara online dan offline kepada karyawan frontliner lembaga keuangan perbankan. Selain itu, pengumpulan data dilakukan dengan wawancara semi-terstruktur untuk mendapatkan informasi tambahan mengenai kepuasan karyawan dan pengaruhnya terhadap lembaga keuangan perbankan. Jumlah data terkumpul pada penelitian ini adalah sebanyak 71 .

\section{Analisis Data}

Analisis data yang dilakukan adalah analisis deskriptif mean dan standar deviasi untuk menentukan nilai peringkat dari masing-masing indikator. Pada tahap analisis juga dibuat scatter plot untuk menggambarkan posisi dari masing-masing indikator yang digunakan dalam penelitian.

\section{Indikator Kepuasan Karyawan}

Indikator yang digunakan dalam penelitian ini antara lain adalah Gaji dan promosi, pelatihan dan pengembangan, beban kerja, kondisi fisik tempat kerja, peraturan tempat kerja, pemberdayaan dan partisipasi, penghargaan dan pengakuan kerja, pengawasan, kerjasama tim, dan kepuasan kerja keseluruhan

\section{ANALISIS DAN DISKUSI}

\section{A. Analisis Deskriptif Peringkat Faktor Kepuasan Karyawan Frontliner}

Sebelum melakukan analisis deskriptif peringkat, beberapa analisis demografi dilakukan untuk menentukan gambaran secara umum dari demografi responden. Hasil yang didapatkan adalah 1 responden bekerja sebagai accounting officer, 33 responden bekerja sebagai teller, 32 responden bekerja sebagai customer service, 1 responden bekerja sebagai penyelia penjualan, dan 4 responden bekerja sebagai analis kredit. Gambar 1 menampilkan proporsi dari masing-masing pekerjaan responden.

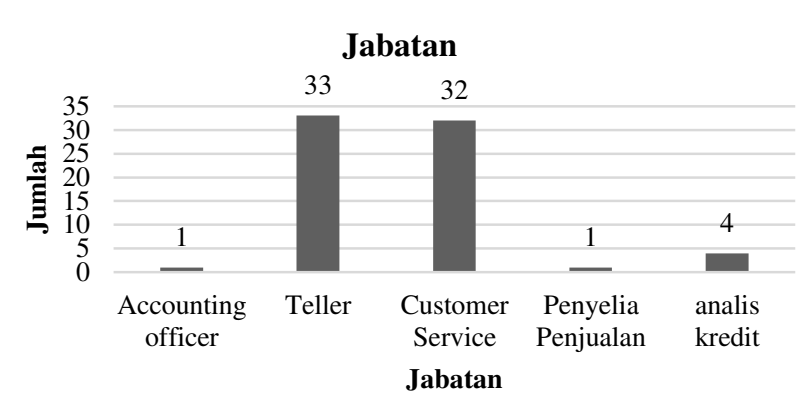

Gambar 1. Proporsi dari masing-masing pekerjaan responden.

Kemudian, setelah mendapatkan hasil dari analisis demografi, analisis yang kemudian dilanjutkan adalah dengan menganalisis peringkat dari masing-masing indikator yang mempengaruhi kepuasan karyawan frontliner lembaga keuangan perbankan. Tabel 1 dan Gambar 2 menampilkan nilai rata-rata dan standar deviasi dari masing-masing indikator kepuasan kerja karyawan.

Dengan mengasumsikan garis imajiner pada posisi rata-rata (Sumbu X) dengan nilai 2,5 dan standar deviasi (Sumbu Y) dengan nilai 0,5 dapat dikatakan bahwa seluruh variabel berada pada posisi kuadran kedua. Peringkat tertinggi dalam kategori persetujuan variabel kepuasan kerja responden adalah pelatihan dan pengembangan. Program pelatihan dan pengembangan karyawan sangat penting untuk mempermudah penyelesaian pekerjaan oleh karyawan. Selain itu, juga dapat dipergunakan untuk membangun modal intelektual perusahaan [11]. Diikuti dengan pengawasan, kondisi fisik tempat kerja, kepuasan kerja keseluruhan, peraturan tempat kerja, gaji dan promosi, beban kerja, kerjasama tim, penghargaan dan pengakuan kerja, dan pemberdayaan dan partisipasi. Pelatihan dan pengembangan disebutkan sebagai persetujuan paling tinggi yang diberikan oleh responden. Sewaktu peneliti melakukan wawancara terhadap salah satu dari responden, responden memang menyatakan bahwa perusahaan tempatnya bekerja sadar dengan betul pentingnya pelatihan dan setiap karyawan yang ada di dalam perusahaan pernah diikutkan pelatihan baik itu pelatihan bersama maupun pelatihan pribadi. 
Tabel 1.

Nilai Rata-rata dan Standar Deviasi Masing-Masing Indikator Kepuasan Kerja

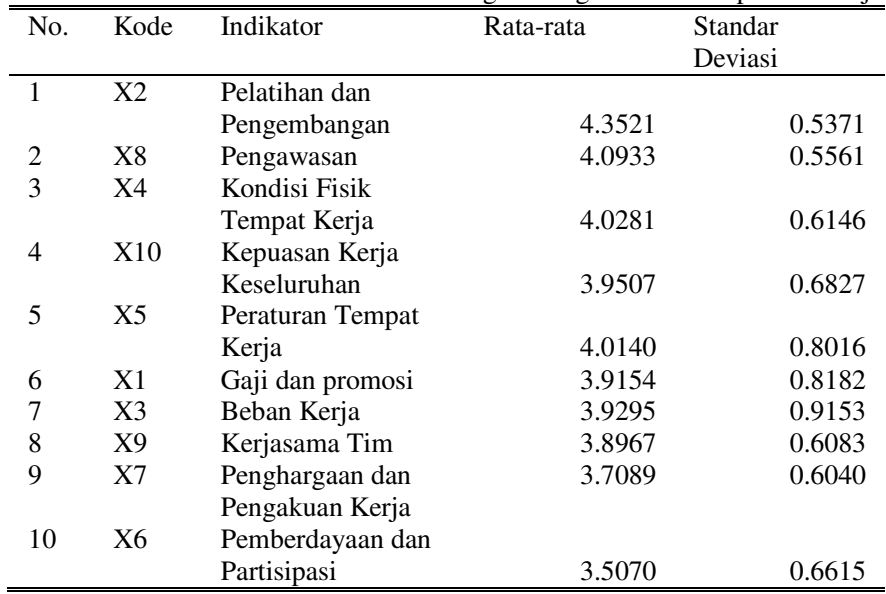

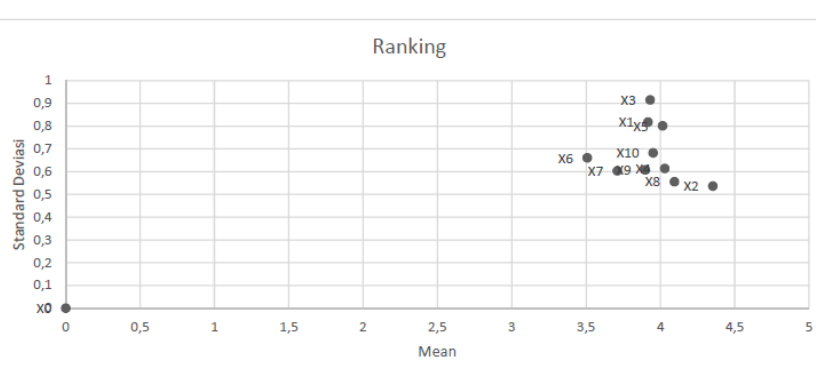

Gambar. 2 Peringkat persetujuan faktor-faktor kepuasan kerja karyawan.

Terkait dengan pengawasan, peneliti melakukan wawancara dengan dua narasumber berbeda, yaitu customer service dan asisten penjualan dari sebuah lembaga keuangan perbankan. Narasumber pertama yaitu customer service memang menyatakan bahwa supervisor tempatnya bekerja memang memberikan bantuan yang sangat besar bagi narasumber dalam bekerja dan bantuan-bantuan lainnya. Supervisor bersedia untuk mendengarkan setiap permasalahan yang tidak bisa diselesaikan oleh customer service dan kemudian membantu untuk melayani konsumen. Tidak sebatas hal itu saja, narasumber yang bekerja sebagai asisten penjualan juga mengatakan bahwa sepengalamannya bekerja sebagai customer service, narasumber mendapatkan bantuan yang sangat banyak dari supervisor-nya, hingga menganggap supervisor seperti ibu kedua di tempat kerja. Bahkan, supervisor tersebut membantu narasumber untuk mendapatkan promosi di tempat kerjanya.

Untuk aspek-aspek selanjutnya seperti kondisi fisik tempat kerja, peneliti mengobservasi tempat kerja beberapa kantor cabang pembantu lembaga keuangan perbankan yang ada di wilayah Surabaya. Terlihat secara jelas bahwa lingkungan kerja bagi karyawan frontliner dapat dikatakan sangat nyaman. Ruangan yang dilengkapi dengan pendingin ruangan lebih dari satu, kursi kerja yang nyaman, dan meja kerja yang diasumsikan oleh peneliti cukup luas. Pada beberapa kantor cabang pembantu, ruangan kerja dilengkapi dengan pengharum ruangan beraroma terapi. Tentu saja ruangan yang seperti itu membuat kondisi fisik tempat kerja menjadi nyaman.

Untuk variabel kepuasan kerja keseluruhan, peraturan tempat kerja, gaji dan promosi, beban kerja, kerjasama tim, dan penghargaan dan pengakuan kerja, setiap responden dari berbagai jenis lembaga keuangan mempunyai jawaban yang bervariasi. Dengan narasumber wawancara yang sama, peneliti juga mendapatkan informasi bahwa peraturan tempat kerja memang cenderung tidak memberatkan, gaji dan promosi yang sesuai dengan beban kerja, serta teman kerja yang sangat mudah untuk diajak kerjasama dan saling berbagi. Untuk variabel penghargaan dan pengakuan kerja, setiap responden mempunyai jawaban yang berbeda-beda. Memang ada perusahaan yang memberikan penghargaan dan pengakuan kerja untuk karyawan frontliner-nya, tetapi ada perusahaan yang tidak memberikan penghargaan dan pengakuan kerja untuk karyawan frontliner-nya secara langsung, tetapi masuk ke dalam sistem penggajian seperti jawaban yang diberikan oleh narasumber dalam wawancara.

Untuk pemberdayaan dan partisipasi, hal yang dimaksudkan dalam penelitian adalah partisipasi karyawan frontliner dalam rapat maupun pengambilan keputusan dalam bekerja. Dari jawaban-jawaban yang diberikan oleh responden, beberapa responden memang tidak pernah berpartisipasi untuk pembuatan keputusan di tempat kerja, jarang berpartisipasi secara aktif dalam rapat, tetapi memang karyawan-karyawan diberdayakan agar bisa berinisiatif dalam bekerja. Hasil tersebut kemudian dicocokkan dengan hasil jawaban wawancara terhadap narasumber customer service. Narasumber customer service menyatakan bahwa memang rapat untuk pengambilan keputusan jarang sekali diadakan dengan mengundang customer service maupun teller. Rapat yang diadakan hanya sebatas briefing ketika pagi hari untuk berdiskusi secara singkat terkait hasil kerja kemarin atau pengalaman menarik lainnya. Maka dari itu, dapat disimpulkan bahwa memang customer service atau teller tidak terlalu diberdayakan untuk pengambilan keputusan dalam bekerja.

\section{KESIMPULAN}

Dari 10 indikator yang ditanyakan kepada responden karyawan frontliner, pelatihan dan pengembangan mendapatkan peringkat tertinggi. Sedangkan peringkat terendahnya adalah pemberdayaan dan partisipasi.

\section{DAFTAR PUSTAKA}

[1] S. D. Meilinda, "Kompasiana," 2015. [Online]. URL: http://www.kompasiana.com/selvidiana/catatan-tentang-layanan-tellerbri-capem_5509b843a333119d762e3b38. [Diakses 6 Maret 2017].

[2] C. G. Chi and D. Gursoy, "Employee Satisfaction, Customer Satisfaction, and Financial Performance : An Empirical Examination," International Journal of Hospitality Management, vol. 28, hal. 245 253, 2009.

[3] M. U. Hassan, S. Tabasum and R. Luqman, "Impact of Employee Satisfaction on Financial Performance Through Mediating Effect of Customer Satisfaction : A Case Study of Life Insurance Corporation of Pakistan," Science International, vol. 25, no. 4, hal. 957 - 963, 2013.

[4] C. Cheung, H. Kong and H. Song, "How to Influence Hospitality Employee Perceptions on Hotel Brand Performance ?," International Journal of Contemporary Hospitality Management, vol. 26, no. 8, hal. 1162 - 1178, 2014.

[5] J. L. Heskett, T. O. Jones, G. W. Loveman, W. E. S. Jr. and L. A. Schlesinger, "Putting the Service-Profit Chain to Work," Harvard Business Review, Harvard, 2008.

[6] K. R. P. Dewi, N. P. Negoro and Y. Rahmawati, "Conceptual 
Framework of Intellectual Capital Influences to Corporate Efficiency," IPTEK Journal of Proceeding Series, vol. 1, no. 1, hal. 48, 2016.

[7] R. A. Noe, J. R. Hollenback, B. Gerhart and P. M. Wright, Human Resource Management - Gaining A Competitive Advantage, 6e ed., Singapore: McGraw Hill, 2008.

[8] A. Turkyilmaz, G. Akman, C. Ozkan and Z. Pastuszak, "Empirical Study of Public Sector Employee Loyalty and Satisfaction," Public Sector Employee Loyalty, vol. 111, hal. 5, pp. 675 - 696, 2011.

[9] A. Naseem, S. E. Sheikh and P. K. P. Malik, "Impact of Employee Satisfaction on Success of Organization : Relation Between Customer Experience and Employee Satisfaction," International Journal of Multidisciplinary Sciences and Engineering, vol. 2, no. 5, hal. 41 - 46,
2011.

[10] V. Gordon, J. Jeffery L. Osgood and J. Phillips, "Municipal Clerks : Examining A Model of Job Satisfaction," Public Personnel Management, vol. 39, no. 4, hal. 327 - 352, 2010.

[11] K. R. P. Dewi, N. P. Negoro and Y. Rahmawati, "Peran Human Capital Terhadap Efisiensi Perusahaan Perbankan di Indonesia," Jurnal Sains dan Seni ITS, vol. 6, no. 1, hal. 18-23, 2017. 